\title{
Hatchability, Growth Performance, Feed Efficiency, and Survival of Normal Feathered Local, Sasso-rir and Their F1-cross Chickens Under on-station Management Condition in Southern Ethiopia
}

shewangizaw woltamo wolde ( $\nabla$ shewangizaw2009@yahoo.com )

SARI https://orcid.org/0000-0002-5199-7811

Tadele Mirkena

FAO

Aberra Melesse

Hawassa University

Tadelle Dessie

ILRI: International Livestock Research Institute

Solomon Abegaz

EIAR: Ethiopian Institute of Agricultural Research

\section{Research Article}

Keywords: Chicken genotype, cross breeding, dual purpose chicken, egg hatchability, mortality

Posted Date: June 17th, 2021

DOI: https://doi.org/10.21203/rs.3.rs-569999/v1

License: (c) (1) This work is licensed under a Creative Commons Attribution 4.0 International License.

Read Full License 


\section{Abstract}

The Normal Feathered local chicken (LL), Sasso-RIR (SRSR) and their F1-cross (LSR) chickens were hatched to evaluated for egg hatchability, growth performance, feed efficiency and survival rate. After 14days of brooding, 150 chicks of each genotype were randomly selected and further replicated in to five pens in a deep litter grower house consisting of 30 chicks each in a completely randomized design, and evaluated for a period of 16-weeks. Hatchability of fertile eggs was highest for LL (80.0\%), intermediate for LSR $(68.6 \%)$ and lowest for SRSR (55.9\%) chickens. The body weight (BW) of chicks at 2-weeks of age was $80.0,76.3$ and $61.5 \mathrm{~g} /$ bird for SRSR, LSR, and LL, respectively, the latter being the lowest $(p<0.05)$. The respective BW at 8-weeks of age was 732,587 and $451 \mathrm{~g}$ while at 18 -weeks it was 1877 , 1379 and $1070 \mathrm{~g} /$ bird and different from each other ( $\mathrm{p}<0.05)$. During 3- to 8-weeks and 9- to 18-weeks growth periods, the $L L$ chickens were inferior $(p<0.05)$ in feed intake $(29.7$ and $66.9 \mathrm{~g} / \mathrm{d} / \mathrm{bird})$ whereas the SRSR chickens were superior ( $p<0.05$ ) in body weight gain ( 15.5 and $16.3 \mathrm{~g} / \mathrm{d} / \mathrm{bird}$ ) and feed conversion ratio (2.67 and $5.35 \mathrm{~g}$ feed/ g gain), respectively. The mortality rate of chicken was not affected by genotypes. It can be concluded that the exotic blood of Sasso-RIR chicken had played a significant role in upgrading the growth rate and market weight of the local Normal Feathered chicken without adverse effect on hatchability, feed efficiency, and survival rate.

\section{Introduction}

Chicken production makes significant contributions to household food security throughout the developing countries. In Ethiopia, egg production followed by income and meat production were the objectives of chicken production (Nigussie et al. 2010). Therefore, large body size, less illness and good physical appearance for cocks whereas production of more eggs, large body size and chicks with high survival rate for hens were the preferred traits in Ethiopia (Nigussie et al. 2010; Tadelle, 2017).

The total chicken population in Ethiopia is estimated at 59.42 million head composed of 50.91, 4.35, and 4.16 million indigenous, hybrid and exotic breeds, respectively (CSA, 2018). In addition to numerous availability, indigenous chickens are adapted to various production constraints, hard eggshells, high fertility and hatchability as well as high dressing percentage. However, egg production, growth rate, and sexual maturity performances, etc. are low compared to exotic chicken (Aberra et al. 2011).

One of the chicken development initiatives in Ethiopia has been by Ethio-chicken plc. with a focus on Sasso-RIR breed. It distributes chicken of this breed to rural and urban households so that it is crossing with the local chicken ecotypes. The Sasso-RIR chicken was previously rated the best for egg production and the second best breed in terms of body weight compared to Kuroiler, Koekoek and improved Horro under on-station condition in Ethiopia (Tadelle, 2017). The same author also reported that the chicken was $170 \%$ and $160 \%$ superior in terms of body weight and egg production, respectively compared to Ethiopian local chicken. Habtie (2019) also reported that Sasso-RIR chicken was the best for egg production compared to Kuroiler, Koekoek and Sasso chickens under on-farm conditions in northern Ethiopia. 
Normal Feathered local chicken (NFLC) comprises about $98 \%$ of the total local chicken population in Ethiopia (Nigussie et al., 2010). However, no attempt has been made to assess production performances of crossbred chicken it with the commercial dual purpose chicken distributed (Sasso-RIR). Consequently, the combining abilities of beneficial traits of both genotypes for production and adaptation performances need to be evaluated. Hence, the objective of this study was to compare three chicken genotypes (NFLC, Sasso-RIR, and NFLC male $x$ Sasso-RIR female crosses) for fertility and hatchability eggs, growth performance, feed intake, feed conversion efficiency, and mortality rate under on-station management conditions.

\section{Materials And Methods}

\section{Description of study site}

The experiment was carried out at Poultry Farm of School of Animal and Range Sciences, College of Agriculture, Hawassa University, Hawassa. Hawassa is located at $273 \mathrm{~km}$ South of Addis Ababa, Ethiopia, at $7^{\circ} 4^{\circ} \mathrm{N}$ latitude and $38^{\circ} 31^{\circ} \mathrm{E}$ longitude at an altitude of $1650 \mathrm{~m}$ above sea level. The area has a bimodal rainfall that ranges between 674 and $1365 \mathrm{~mm}$ annually. The mean temperature ranges between $13.5^{\circ} \mathrm{C}$ and $27.6^{\circ} \mathrm{C}$ (NMA-Hawassa Branch Directorate 2012).

\section{Sources of chicken genotypes}

Hundred-forty (120 female and 20 male) 45-day old chicks of Sasso-RIR and 600 fertile eggs of NFLC were purchased to establish the experimental flocks. The Sasso-RIR chicks were purchased from agents of Ethio-chicken poultry breeding farms in Hawassa, Ethiopia. The eggs of NFLC were purchased from individual rural households in Bolosso-Sore and Humbo districts in Wolaita zone of southern Ethiopia and hatched at Hawassa Agricultural Research Center and then brooded and reared at Hawassa University, College of Agriculture.

\section{Mating plan of chicken and hatching of eggs}

Mating of Sasso-RIR cock with Sasso-RIR hen, Normal Feathered local cock with Normal Feathered local hen, and Normal Feathered local cock with Sasso-RIR hen was made naturally by putting a cock and a hen together in a separate pen to produce Sasso-RIR (SRSR), Normal Feathered local (LL) and their F1crosses (LSR), respectively. A total of 10 males and 60 females were mated to produce each of SRSR and LSR genotypes whereas 19 males and 114 females were mated to produce LL genotype. The laid eggs were collected on daily basis for 15 consecutive days, then screened based on physical appearances and hatched at the Poultry Farm of the School of Animal and Range Sciences.

\section{Management of experimental chicken}

After hatching, all chicks were kept in a brooder house and placed separately according to their genotype. After 14-days of brooding, 150 chicks of each genotype were randomly selected and further replicated in 
to five pens in grower house consisting of 30 chicks each in a completely randomized design. Chicks were kept in a deep litter housing system with concrete floors covered with wood shavings at a depth of 5 $\mathrm{cm}$ and pens divided by mesh wire. The room and chicken rearing equipment were cleaned and disinfected prior to two weeks of the beginning of experiment. An electric bulb of $100 \mathrm{w}$ was used in each pen as a heat and additional light sources. Water and feeds were offered on ad lib basis. All genotypes were fed the same standard commercial dual purpose chicken feed as per the recommended feeding schedules by the manufacturer (Alema Koudijs Feed Plc, Debrezeit, Ethiopia) (Table 1). All chickens were vaccinated against Newcastle, Marek's and infectious bursal diseases as per the recommended vaccination schedules of the manufacturer. Coccidiostat (Amprolium $20 \%$ powder) was also administered as indicated by the manufacturer.

Table 1: Chemical composition of commercial dual purpose chicken feeds used in the study

\begin{tabular}{|lllll|}
\hline Nutrient composition & \multicolumn{4}{l}{ Age (weeks) } \\
\cline { 2 - 5 } & $0 \rrbracket 3$ & $4 \llbracket 7$ & $8-17$ & $>17$ \\
\hline Crude protein, \% & 20.9 & 18.5 & 15.5 & 16.0 \\
\hline Crude fiber, \% & 4.50 & 5.80 & 8.00 & 7.00 \\
\hline Crude fat, \% & 3.00 & 5.00 & 5.00 & 5.00 \\
\hline Calcium, \% & 1.15 & 0.90 & 0.80 & 3.55 \\
\hline Phosphorus, \% & 0.55 & 0.49 & 0.43 & 1.85 \\
\hline Energy (kcal/kg) & 3035 & 2950 & 2750 & 2800 \\
\hline
\end{tabular}

\section{Data collection}

Fertility (\%) and hatchability (\%) were calculated from the data collected at day 1 (number of eggs set), day 18 (fertile eggs by candling) and day 21 (number of chicks hatched). Individual weight of eggs set and chicks hatched were recorded. Feed offered and refusals were weighed and recorded daily in the morning on pen basis. Feed intake was then computed by difference by subtracting feed refusal from that of offered. Average daily intake per chick was computed by dividing total feed intake per chick by the duration of the experiment. The individual pen average body weight of unsexed chicks was recorded on weekly basis until 7-weeks of age. After 8-weeks of age, the average values of each of the female and male chickens weight was recorded separately on pen basis but fed together. The ratios of male to female chickens at 8-weeks of age were $0.99,0.90$ and 0.81 for SRSR, LSR and LL chickens, respectively. Similarly, at the end o 18-weeks, the ratios were 1.14, 1.00 and 0.90 for SRSR, LSR and LL chickens, respectively. Daily weight gain per chick was then computed by difference by subtracting initial body weight from that of final body weight and then dividing this value by the duration of experiment. Feed conversion ratio (FCR) was computed by the ratio of daily feed intake per chick to daily weight gain 
per chick. Number of chicken died was recorded daily on pen basis and mortality was calculated as a ratio of the number of chicken died to the number of chicken a live at initial multiplied by 100 .

\section{Data analysis}

Data on feed consumption and body weight traits (both sex) and FCR were analyzed by two-way ANOVA considering genotype and age as main effects. The data on body weight traits after 8-week were analyzed by two-way ANOVA considering genotype and sex as main effects. Weight of set eggs and hatch weight of chicks were analyzed by one-way ANOVA. The Frequency procedure was employed for hatchability and fertility of eggs, and mortality rate of different genotypes of chicken. Means were separated using Duncan multiple range test. All data were analyzed using Statistical Analysis System (SAS, Ver. 9.3, 2014).

Models that were used:

ANOVA Model 1 (feed intake, body weight and gain (both sex) and FCR)

$Y_{i j k}=\mu+G_{i}+A j+G{ }^{\star} A j+e_{i j k}$ where

$\mathrm{Y}_{\mathrm{ijk}}=$ the observed $\mathrm{K}^{\text {th }}$ variable in the $\mathrm{i}^{\text {th }}$ genotype and $\mathrm{j}^{\mathrm{th}}$ age of chicken

$\mu=$ overall mean

$G_{i}=$ the $i^{\text {th }}$ fixed effect of genotype $(i=S R S R, L S R, L L)$

$A j=$ the $j^{\text {th }}$ fixed effect of age $(j=3-8$ week, $9-18$ week $)$

$\mathrm{Gi}{ }^{\star} \mathrm{Aj}=$ effect due to interaction of genotype with age

$\mathrm{e}_{\mathrm{ijk}}=$ random error

ANOVA Model 2 (body weight and body weight gain)

$Y_{i j k}=\mu+G_{i}+S j+G i^{\star} S j+e_{i j k}$ where

$Y_{i j k}=$ the observed $K^{\text {th }}$ variable in the $i^{\text {th }}$ genotype and $j^{\text {th }}$ sex of chicken

$\mu=$ overall mean

$G_{i}=$ the $i^{\text {th }}$ fixed effect of genotype ( $i=$ SRSR, LSR, LL)

$S j=$ the $j^{\text {th }}$ fixed effect of sex $(j=$ male, female $)$

$\mathrm{Gi}^{\star} \mathrm{Sj}=$ effect due to interaction of genotype with sex 
$e_{i j k}=$ random error

\section{Results}

The effect of chicken genotype on fertility, hatchability, weight of eggs set and hatch weight of chicks for eggs collected from different genotypes are indicated in Table 2. Fertility of set eggs was similar $(p>0.05)$ among genotypes. The hatchability of fertile eggs for SRSR was lower $(p<0.05)$ than LL chickens. SRSR and LSR chickens were similar $(p>0.05)$ but higher $(p<0.05)$ than LL chicken in weight of eggs set and hatch weight of chicks.

Table 2: Fertility, hatchability, weight of eggs set and hatch weight of eggs collected from the three chicken genotypes

\begin{tabular}{llllll}
\multirow{2}{*}{ Parameters } & \multicolumn{2}{l}{ Genotypes } & & \\
\cline { 2 - 6 } & SRSR & LSR & LL & Mean & SD \\
\hline Number of eggs set & 516 & 520 & 568 & 535 & 28.9 \\
\hline Number of fertile eggs & 390 & 405 & 521 & 439 & 71.7 \\
\hline Number of hatched eggs & 218 & 278 & 417 & 304 & 102 \\
\hline Fertility (\%) of set eggs & 75.6 & 77.9 & 91.7 & 83.7 & 11.4 \\
\hline Hatchability (\%) of fertile eggs & $55.9^{\mathrm{b}}$ & $68.6^{\mathrm{ab}}$ & $80.0^{\mathrm{a}}$ & 68.2 & 12.1 \\
\hline *Average weight of set eggs, g/ egg & $53.1^{\mathrm{a}}$ & $52.8^{\mathrm{a}}$ & $40.9^{\mathrm{b}}$ & 48.9 & 6.96 \\
\hline * Hatch weight, g/ chick & $30.8^{\mathrm{a}}$ & $31.2^{\mathrm{a}}$ & $23.8^{\mathrm{b}}$ & 28.6 & 4.16
\end{tabular}

${ }^{a, b} \times 2<0.05$ values differ significantly between genotypes within a row; *Means with different letters within

Table 3 shows growth performance, feed intake and FCR. LL had the lowest $(p<0.05)$ body weight and gains in all study periods. Although SRSR and LSR were similar $(p<0.05)$ body weight at 2-weeks of age, the body weight at 8-week and 18-week and daily growth rate (after 2-weeks and 8-weeks of age) of LSR were lower $(p<0.05)$ than those of SRSR chicken. The body weight of SRSR was superior followed by LSR chicken specially after 4-weeks of age and the values were increased with age (Figure 1). The SRSR consumed similar ( $p>0.05)$ feed as LSR chicken during the first 6-weeks of study but it was higher $(p<0.05)$ for SRSR than LSR chicken during the next 10-weeks of study. The LL chicken consumed lower $(p<0.05)$ feed than SRSR and LSR chickens in all study periods. As shown in Figure 2, the feed intake of all genotypes was increased with birds age. However, SRSR chicken was superior whereas LL chicken was inferior in feed consumption specially after the 4 weeks of age. The feed consumption between LL 
and LSR chickens was similar $(p>0.05)$, while the values were higher $(p<0.05)$ than that of the SRSR chicken to gain the same weight in all study periods.

The results on body weight and gains (Table 4) showed that genotype and sex had significant effects on all study periods, while the interaction effect was insignificant. Within genotypes, male chickens were heavier $(p<0.05)$ than females. However, there were similar $(p>0.05)$ body weight and gains between SRSR female and LSR male, LSR female and LL male chicken. As indicated in Figure 3, SRSR male was superior and LL female was inferior in body weight in all study periods.

Table 5 shows the mortality rate of three chicken genotypes during two study periods. The mortality rate was insignificant ( $p>0.05)$ among genotypes in all periods. The loss was highest during 9 - to 18-weeks of growth.

Table 3: Mean body weight ( $\mathrm{g} / \mathrm{bird})$, body weight gain ( $\mathrm{g} / \mathrm{bird})$, feed intake ( $\mathrm{g} / \mathrm{bird}$ ) and feed conversion ratio ( $\mathrm{g}$ feed intake / $\mathrm{g}$ weight gain) of three chicken genotypes at different growing periods

\begin{tabular}{|c|c|c|c|c|c|c|}
\hline Age & Genotype & IBW & FBW & $A D G$ & DFI & FCR \\
\hline \multirow[t]{5}{*}{ Week 3-8 } & SRSR & $80.0^{a}$ & $732^{a}$ & $15.5^{\mathrm{a}}$ & $41.4^{\mathrm{a}}$ & $2.67^{b}$ \\
\hline & LSR & $76.3^{a}$ & $587^{b}$ & $12.2^{b}$ & $36.8^{a}$ & $3.04^{\mathrm{a}}$ \\
\hline & LL & $61.5^{b}$ & $452^{c}$ & $9.28^{c}$ & $29.7^{b}$ & $3.21^{\mathrm{a}}$ \\
\hline & Mean & 72.6 & 590 & 12.3 & 36.0 & 3.00 \\
\hline & SEM & 0.79 & 7.72 & 0.19 & 1.00 & 0.09 \\
\hline \multirow[t]{5}{*}{ Week 9-18 } & SRSR & $732^{a}$ & $1877^{a}$ & $16.4^{\mathrm{a}}$ & $87.4^{\mathrm{a}}$ & $5.35^{b}$ \\
\hline & LSR & $587^{b}$ & $1379^{b}$ & $11.3^{\mathrm{b}}$ & $78.3^{\mathrm{b}}$ & $6.95^{a}$ \\
\hline & LL & $452^{c}$ & $1070^{c}$ & $8.83^{c}$ & $66.9^{c}$ & $7.61^{a}$ \\
\hline & Mean & 590 & 1441 & 12.2 & 77.5 & 6.64 \\
\hline & SEM & 7.72 & 15.7 & 0.19 & 0.63 & 12.8 \\
\hline
\end{tabular}

Source of variation, $P$-value

\begin{tabular}{lllllll}
\hline Age (A) & $<.0001$ & $<.0001$ & NS & $<.0001$ & $<.0001$ & $<.0001$ \\
\hline Genotype (G) & $<.0001$ & $<.0001$ & $<.0001$ & $<.0001$ & $<.0001$ & $<.0001$ \\
\hline A x G & $<.0001$ & $<.0001$ & NS & NS & NS & NS
\end{tabular}

$a, b, c$ Means within a column with the same letter are not different ( $P>0.05)$ among genotype of the same age; $S E M=$ standard error of means; $I B W=$ initial body weight; $F B W=$ final body weight; $A D G=$ average daily gain; $\mathrm{DFI}=$ daily feed intake; FCR= feed conversion ratio; NS = not significant 
Table 4: Genotype, sex and interaction effects on body weight and gains ( $\mathrm{g} / \mathrm{bird})$ of chicken

\begin{tabular}{llllll} 
Genotype & Sex & 8-week BW & 18 -week BW & TBWG & ADG \\
\hline SRSR & Male & $793^{\mathrm{a}}$ & $2135^{\mathrm{a}}$ & $1341^{\mathrm{a}}$ & $19.2^{\mathrm{a}}$ \\
\hline & Female & $671^{\mathrm{b}}$ & $1618^{\mathrm{b}}$ & $947^{\mathrm{b}}$ & $13.5^{\mathrm{b}}$ \\
\hline LSR & Male & $655^{\mathrm{b}}$ & $1572^{\mathrm{b}}$ & $917^{\mathrm{b}}$ & $13.1^{\mathrm{b}}$ \\
\hline & Female & $519^{\mathrm{c}}$ & $1185^{\mathrm{c}}$ & $667^{\mathrm{c}}$ & $9.52^{\mathrm{c}}$ \\
\hline LL & Male & $508^{\mathrm{c}}$ & $1211^{\mathrm{c}}$ & $704^{\mathrm{c}}$ & $10.5^{\mathrm{c}}$ \\
\hline & Female & $395^{\mathrm{d}}$ & $929^{\mathrm{d}}$ & $534^{\mathrm{d}}$ & $7.63^{\mathrm{d}}$ \\
\hline Overall mean & & 590 & 1442 & 852 & $12.2^{\mathrm{a}}$ \\
\hline SEM & & 6.63 & 15.7 & 16.1 & 0.23
\end{tabular}

Source of variation, $P$-value

\begin{tabular}{llllll}
\hline Age $(\mathrm{A})$ & $<.0001$ & $<.0001$ & $<.0001$ & $<.0001$ & $<.0001$ \\
\hline Genotype (G) & $<.0001$ & $<.0001$ & $<.0001$ & $<.0001$ & $<.0001$ \\
\hline A x G & NS & NS & NS & NS & NS
\end{tabular}

a, b, c, d Means with the same letter within column are not significantly different ( $p>0.05)$; SEM= standard error of means; $B W=$ body weight; $T B W G$ = total body weight gain; $A D G=$ average daily gain; $N S=$ not significant

Table 5: Number of chickens initially used (n) and died, and rate of mortality (\%) of three genotypes of chicken at different stages of development tested on station

Week 3-8 Week 9-18

\begin{tabular}{lllllll} 
Genotype & $\mathrm{n}$ & Died & Mortality & $\mathrm{n}$ & Died & Mortality \\
\hline SRSR & 150 & 7 & 4.67 & 143 & 19 & 13.3 \\
\hline LSR & 150 & 4 & 2.67 & 146 & 22 & 15.1 \\
\hline LL & 150 & 9 & 6.00 & 141 & 25 & 17.7 \\
Mean & & & 4.45 & & & 15.4
\end{tabular}

$\chi 2<0.05$ values not significantly different between genotypes within a column

\section{Discussion}


The comparable fertility of set eggs among genotypes in this study suggests that factors affecting egg fertility such as male to female chicken ratio, length of egg storage and feed were similar across all genotypes (Henery, 2004). The hatchability of fertile eggs for SRSR was below the range $(67.9 \%-89 \%)$ previously reported for local, exotic and their crosses (Misba and Aberra, 2013; Bamidele et al., 2019). However, the hatchability of fertile eggs for all studied genotypes was in agreement with those of Alabi et al. (2012) and Wondmeneh et al. (2011), who reported values ranging from 52.4-87.0\% for local and cross-bred chickens. The eggs of all genotypes were exposed to similar environmental conditions but the lower hatchability of fertile eggs of SRSR was most likely due to genetic factor (King'ori, 2012). The SRSR and LSR chickens were similar but higher than LL chicken in weight of eggs set and hatch weight of chicks suggesting a positive correlation between egg weight and hatch weight in chickens (Abiola et al. 2008).

The significant influence of genotype on body weight and gains, feed intake and feed conversion ratio in this study suggest that genetic differences exist among the genotypes for these traits. The daily body weight gains during the two study periods was largely inconsistent with findings of Wondmeneh (2015) who reported the range of $5.49 \mathrm{~g}$ for indigenous unimproved Horro and $11.59 \mathrm{~g}$ for commercial Bovans Brown chicken during 20-weeks growth period under on-station conditions in Ethiopia. In agreement with present findings, Moujahed and Haddad (2013) and Wondmeneh (2015) observed that the growth rate of local chickens was generally slower than the commercial breeds which is attributed to their poor genetic makeup. The body weights of LL chickens in present study were comparable to the values reported for local kei strain (924 g) (Misba and Aberra, 2013) and improved indigenous Horro (964 g) at 20 weeks of age under on- station conditions (Wondmeneh, 2015). However, the value of body weight for LSR chickens at 18 weeks of age in this study was higher than the values reported for local Kei $x$ RIR cross (1132 g) (Misba and Aberra, 2013) and RIR x improved indigenous Horro cross (1070 g) (Wondmeneh, 2015) at the same age and management conditions may be due to the genetic superiority of Sasso-RIR chickens in body weight than RIR chickens. In line with the values concerning body weight in this study, El-Dlebshany et al. (2009) reported that high body weight chickens had the highest growth rates.

Although SRSR and LSR chickens were similar body weight at hatch and 2-weeks of age, the body weight at 8-weeks and 18-weeks of LSR was lower than those of SRSR genotype suggests that genotype by age interaction effect was exist on this trait, which confirms previous reports by Wondmeneh (2015). The value concerning feed consumption in this study is in agreement with previous studies by Wondmeneh (2015) and Bamidele et al. (2019), who reported more feed consumptions for commercial and crossbred chickens than indigenous chicken. The daily feed intake of chicken during the first 6-weeks of study in the present study was closer to the daily intakes of Kei $(25.2 \mathrm{~g} /$ day), Key-Fayoumi cross ( $27.0 \mathrm{~g} / \mathrm{day})$ and KeiRIR cross (24.4 g/day) chickens at similar age in Ethiopia (Misba and Aberra, 2013). Feed consumption of chicken genotypes during the next 10-weeks of study was increased which is comparable with previously reported figures for unimproved Horro ( $58.4 \mathrm{~g} /$ day) and Fayoumi chicken $(71.4 \mathrm{~g} /$ day) (Tesfa, 2013; Wondmeneh, 2015). The lowest feed consumption of LL chickens might be due to low maintenance requirement as a result of lowest body weight in all study periods. The feed intake of all genotypes was increased as the age increased suggesting the direct proportional relationship between feed intake and 
body weight (Balami et al. 2018). The LL and LSR chickens consumed more feed than that of the SRSR chickens to gain the same weight in all study periods are in good agreement with reports by Wondmeneh (2015), who described that indigenous Horro chicken utilized feed inefficiently than commercial Bovans Brown during growing period. A probable explanation is that the body weight gain is mainly related to the feed consumption and to the feed efficiency, which depends on the physiological condition of the birds, climatic change and other factors (Azharul et al.,2005). Inconsistent with the present findings, Rudzani et al. (2017) reported similar feed conversion ratio for Ross and Cobb genotypes during brooding and growth periods. During the period of 9-week to 18-week of study, birds seems to require higher feed than periods of 3-week to 8-week of study to bring the same weight which could be explained by increases in their activity (movement) and making noise loudly with age, require more maintenance energy (Tabinda et al. 2013).

The values about sex effect on body weight and gains in present study are in good agreement with the reports of Kow et al. (2015) who observed that the body weight of male Ross and Cobb broiler chicken breeds were superior to their female counterparts during the growth periods in South Africa. Within genotype, the heavier body weight of male chickens than female chickens in this study might be due to males are greater in feed competition, socially dominate females, higher in nutrient requirement, and different from females in hormone for growth (Zerehdaran et al. 2004). However, among genotypes, the similarity in body weight between SRSR female and LSR male, and LSR female and LL male chickens suggest the similarity in nutrient requirement and feed intake between these chickens.

In line with present study, Udeh et al. (2015) reported that mortality rate among Arbor Acres, Marshall, and Ross was not significant under intensive management conditions. On the contrary, Wondmeneh (2015) observed that the survival rate of Bovan Brown (98.9\%) and improved Horro (98.8\%) was higher than unimproved Horro (88.8\%) and RIR-Horro cross (87.1\%) chicken under on-station conditions in Ethiopia. The mortality rate in present study was in accordance with Misba and Aberra (2013) and Ali et al. (2012), who observed that the increased rate of mortality with age. The major environmental factors responsible for increased rate of mortality during 9- to 18-weeks of age in present study was the prevalence of disease (coccidiosis).

In general, the hatchability of LSR chickens was similar to LL chickens but it was the least for SRSR chickens. Next to SRSR chickens, LSR chickens were higher than LL chickens in terms of growth rate and market weight. Feed efficiency was best for SRSR chickens and worst for LSR and LL chickens. The use of exotic blood of Sasso-RIR chickens to cross with Normal Feathered local chickens had played a significant role in upgrading the growth rate and market weight for F1-crosses without adverse effect on hatchability, feed efficiency, and survival rate and is a topic of further investigation.

\section{Declarations}

Statement of animal rights: All applicable international, national, and institutional guidelines for the care and use of animals were followed. Study was reviewed and approved by the School of Animal and Range 
Sciences, College of Agriculture, Hawassa University.

Conflict of interest: we declare that we have no conflict of interest.

Data availability statement: The datasets generated during and/or analyzed during the current study are available from the corresponding author on reasonable request.

\section{Acknowledgements}

This study was funded by grants from the African Chickens Genetic Gain project. The authors are grateful to Southern Agricultural Research Institute for granting education leave for the first author. We also sincerely thank School of Animal and Range Sciences, College of Agriculture, Hawassa University for the research materials support.

\section{References}

Aberra, M., Maak, S., Schmidt, R., von Lengerken, G., 2011. Effect of long-term heat stress on some performance traits and plasma enzyme activities in Naked-neck chickens and their F1 crosses with commercial layer breeds, Livestock Science, 141, 227-231.

Abiola, S. S., Meshioye, O. O., Oyerinde, B. O., Bamgbose, M.A., 2008. Effect of egg size on hatchability of broiler chicks, Archivos de zootecnia, 57, 83-86.

Alabi, O. J., Ng-ambi, J. W., Norris, D., Mabelebele, M., 2012. Effect of egg weight on hatchability and subsquent performance of Potchefstroom Koekoek chicks, Asian Journal of Animal and Veterinary Advances, 7, 718-725.

Ali, M.I., Azmal, S.A., Ali, A., Faruque, M.O., 2012. Effect of density and flock size on growth performance of native chicken, Journal of Bangladesh Agricultural University, 10, 55-59.

Azharul, I.M., Ranvig, H., Howlider, M.A.R., 2005. Comparison of growth rate and meat yield characteristics of cockerels between Fayoumi and Sonali under village conditions in Bangladesh, Livestock Research for Rural Development, 17, 3-6.

Balami, A.G., Enam, S.J., Sule, A.G., Patrobas, M.N., Abdu, P.A., Chiroma, M.A., Wakawa, A.M., Aluwong, T., 2018. The relationship between feed conversion ratio, feed intake and body weight gain of broilers fed moringa oleifera leaf supplemented feed following challenged with very virulent infectious bursal disease virus, Advances in Animal and Veterinary Science, 6, 227-233.

Bamidele, O., Sonaiya, E. B., Adebambo, O.A., and Dessie, T., 2019. On-station performance evaluation of improved tropically adapted chicken breeds for smallholder poultry production systems in Nigeria, Tropical Animal Health and Production, 52, 2-6. 
CSA., 2018. Central Statistics Authority. Agricultural sample survey 2017/18. Report on livestock and livestock characteristics, 2. Statistical Bulletin No. 578. Addis Ababa, Ethiopia.

El-Dlebshany, A. E., El-Tahawy, W.S., Amin, E.M., 2009. Inheritance of some blood plasma constituents and its relationship with body weight in chickens, Egypt Poultry Science, 29, 465-480.

Habtie A., 2019. Characterization of chicken production system and on-farm evaluation of introduced exotic chicken breeds in Gonder zuria and Kalu districts of Amhara region, Ethiopia, MSc Thesis, Haramaya University, Ethiopia, pp. 47-49

Henry, R.W., 2004. Hatchability Problem Analysis. Department of Dairy and Poultry Sciences, Cooperative Extension Service, Inst. Food and Agricultural Science, University of Florida, Gainesville FL 32611.

Kingori, A.M. , 2012. Review of the factors that influence egg fertility and hatchability in poultry, International Journal of Poultry Science, 10, 483-492.

Kow, B., Thendo, S.T., Avhafunani, J.N., Kgabo, T.M., 2015. Effects of genotype and sex on the growth performance and carcass characteristics of broiler chickens, Tropical Animal Health and Production, 850, $1-7$.

Misba, A., Aberra, M., 2013. Evaluating the growth performance of local kei chickens and their F1-crosses with Rhode Island Red and Fayoumi breeds in watershed areas of Gurage administrative zone, Southern Ethiopia, Tropical and Subtropical Agro-ecosystems, 16, 39-50.

Moujahed, A., Haddad, B., 2013. Performance, livability, carcass yield and meat quality of Tunisian local poultry and fast-growing genotype (Arbor Acres) fed standard diet and raised outdoor access, Journal of Animal Production Advances, 3, 75-85.

NMA., 2012. National Metrological Agency, Hawassa Branch Directorate, Annual metrological report, Hawassa, Ethiopia.

Nigussie, D., Liesbeth, H., van der, W., Tadelle, D., van- Arendonk, J.A.M., 2010. Production objectives and trait preferences of village poultry producers of Ethiopia: implications for designing breeding schemes utilizing indigenous chicken genetic resources, Tropical Animal Health and Production, 42,1519-1529.

Rudzani, S., Joseph, J.B., Mashudu, D.R., Kow, B., 2017. Effects of stocking density and genotype on the growth performance of male and female broiler chickens, Asian Journal of Poultry Science, 11, 96-104.

SAS., 2014. Statistical Analysis System User's Guide, Version 9.3 for windows. Statistical Analysis Institute, Inc, SAS Camp Drive Cary, North Carolina, USA.

Tadelle, D., 2017. Progress Narrative report on African Chicken Genetic Gains Program. International Livestock Research Institute (ILRI), Addis Ababa, Ethiopia. 
Tabinda, K., Sohail, H.K., Nasir, M., Abida, P., Tanveer, A., 2013. Comparative study of growth performance, meat quality and haematological parameters of three-way crossbred chickens with reciprocal F1 crossbred chickens in a subtropical environment, Journal of Applied Animal Research, 41, 300-308.

Tesfa G, Samson, L., Endalew, B., 2013. Production performance of Fayoumi chickens under intensive management condition of Adami Tulu Agricultural Research Center, International Journal of Livestock Production, 4, 172-176.

Udeh, I., Ezebor, P. N., Akporahuarbo, P.O., 2015. Growth performance and carcass yield of three commercial strains of broiler chickens raised in a tropical environment, Journal of Biology, Agriculture and Healthcare, 2, 62-67.

Wondmeneh, E., Dawud, I., Adey, M., 2011. Comparative evaluation of fertility and hatchability of Horro, Fayoumi, Lohmann Silver and Potchefstroom Koekoek breeds of chicken, Asian Journal of Poultry Science, 5, 24-129.

Wondmeneh, E., 2015. Genetic improvement in indigenous chicken of Ethiopia. PhD Thesis. Wageningen Univ., The Netherlands, pp. 74 - 78.

Zerehdaran, S., Vereijken, A. L. J., van Arendonk, J.A. M., van der Waaij, E.H., 2004. Effect of age and housing system on genetic parameters for broiler carcass traits, Poultry Science, 84, 833-838.

\section{Figures}




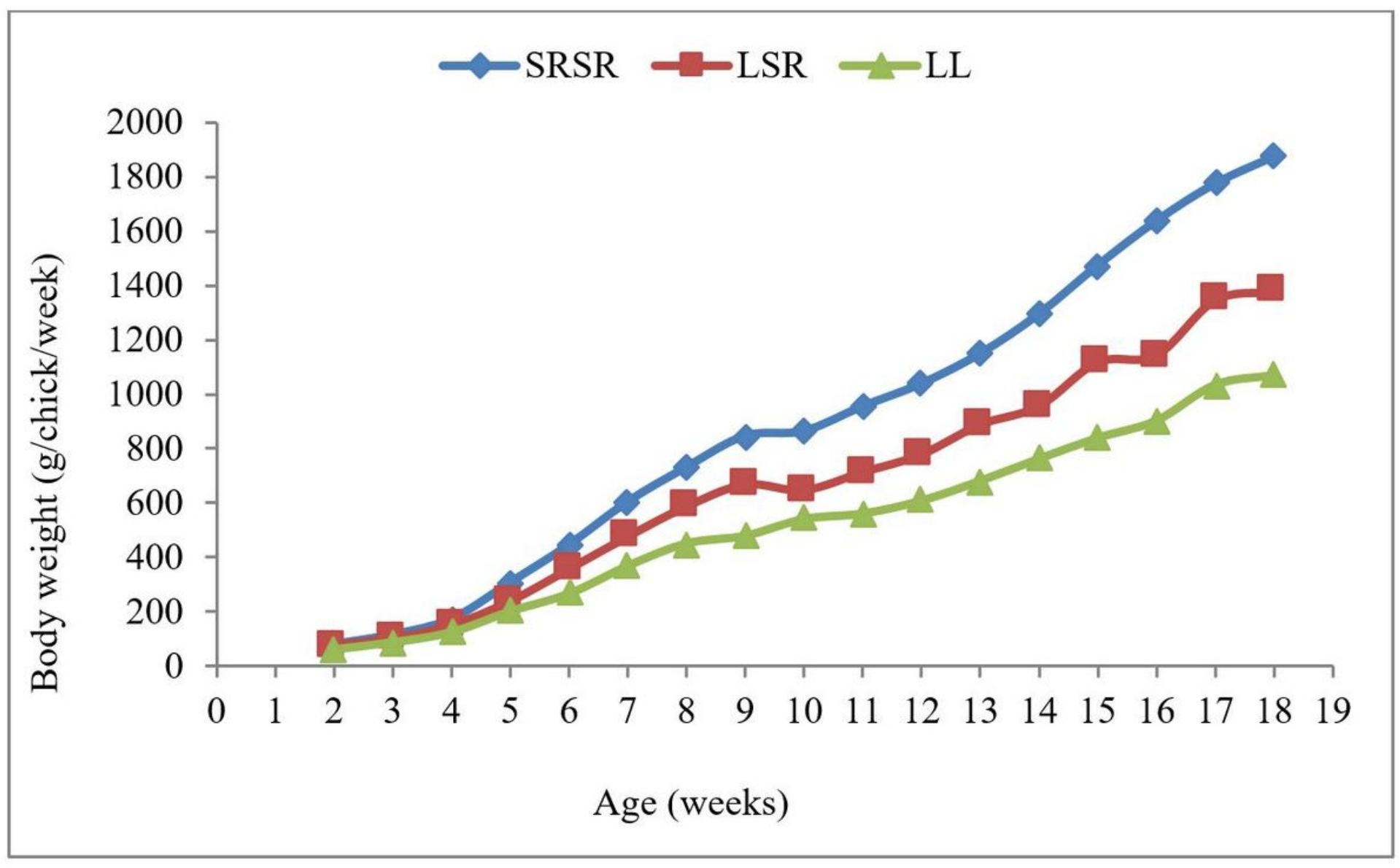

Figure 1

Body weight of three chicken genotypes at different experimental period 


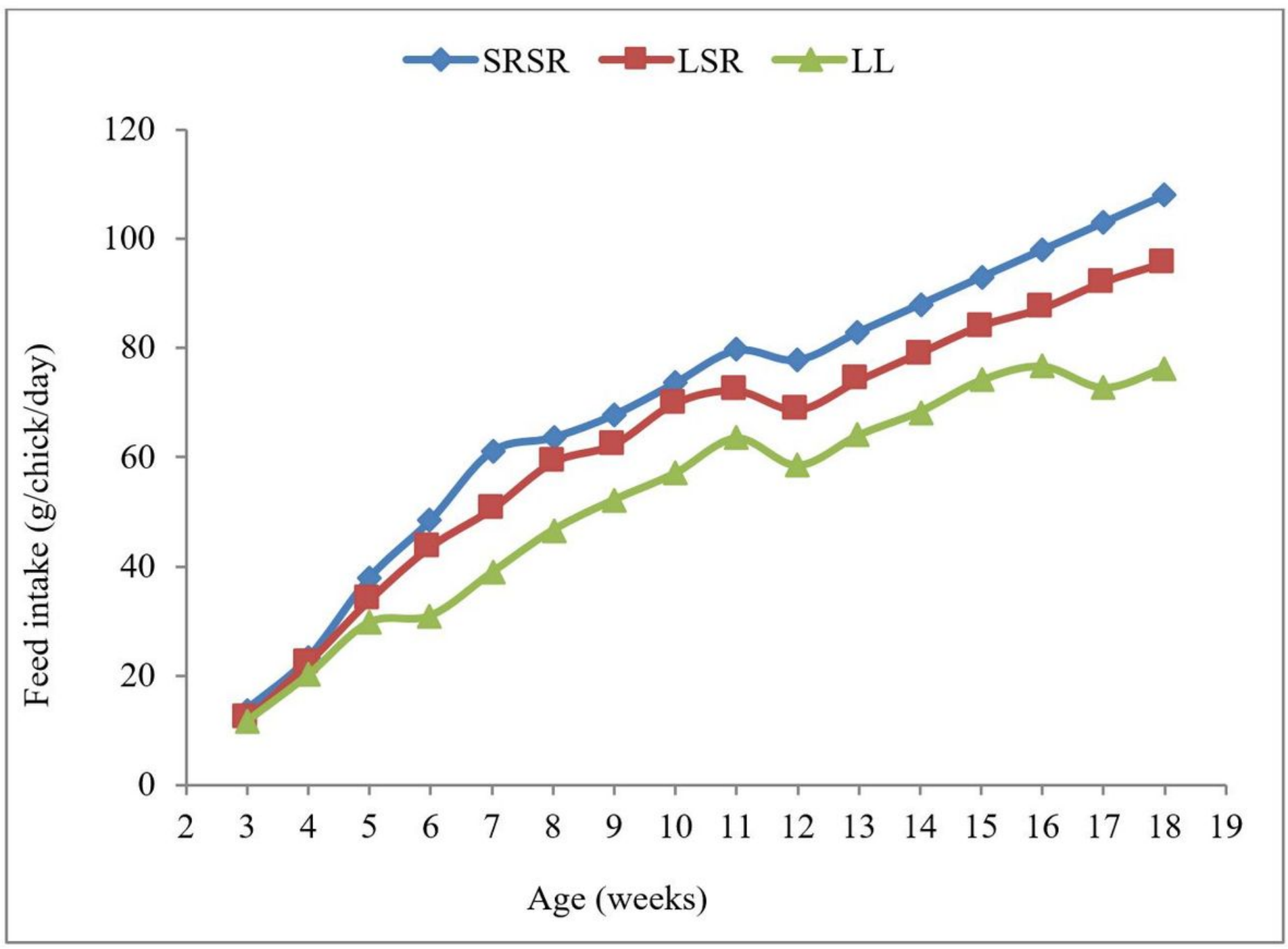

Figure 2

Feed intake of three chicken genotypes at different experimental period 


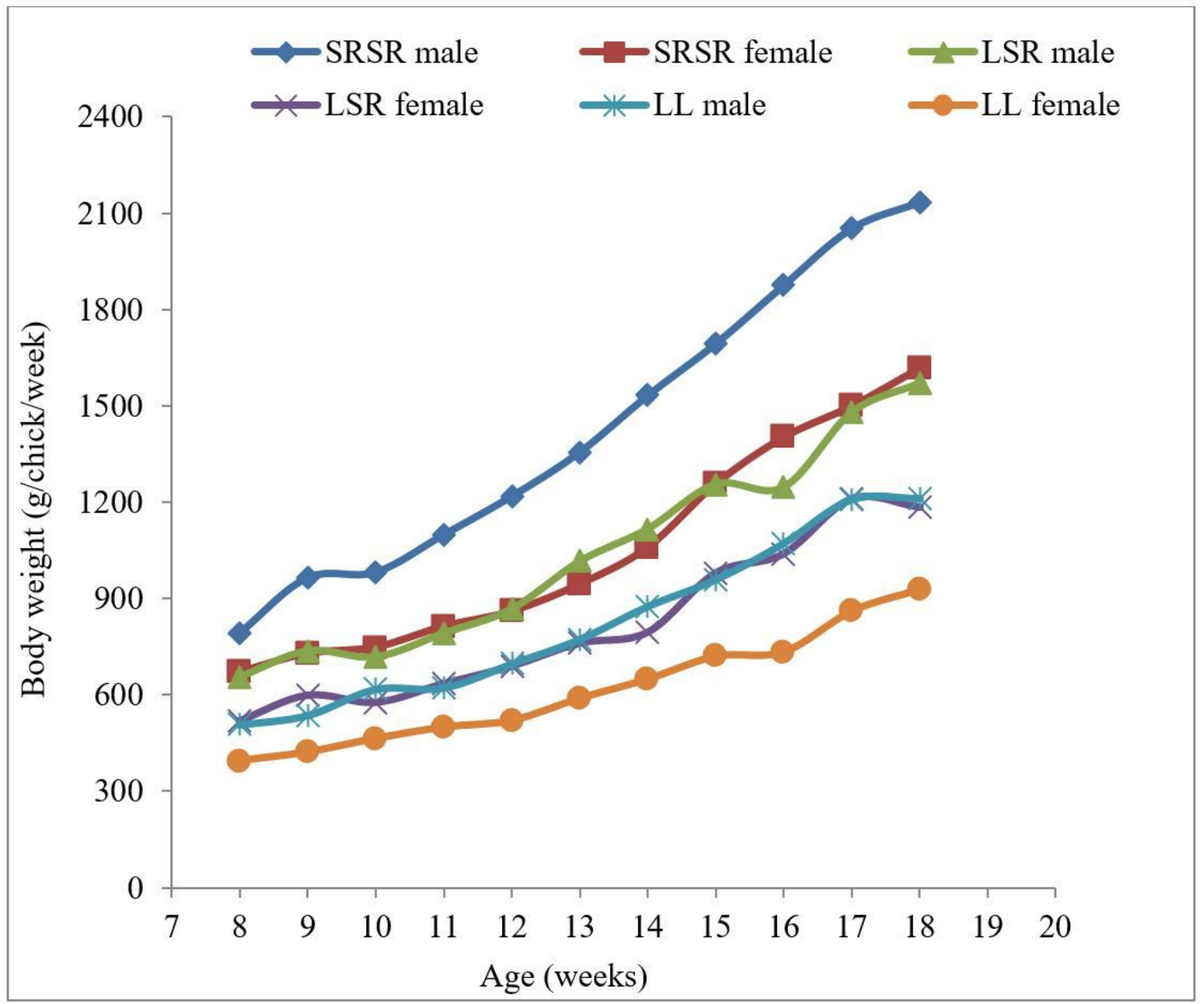

Figure 3

The male and female chicken body weights of three genotypes from 8- to 18-weeks of study 